\title{
P02.147. Emotions matter: sustained reductions in chronic non-structural pain after a brief, manualized emotional processing program
}

\author{
H Schubiner $^{1 *}$, A Burger $^{2}$, M Lumley $^{3}$ \\ From International Research Congress on Integrative Medicine and Health 2012 \\ Portland, Oregon, USA. 15-18 May 2012
}

\section{Purpose}

Current treatments for chronic pain have limited effectiveness. Although major life stressors are elevated in those with chronic pain, emotional awareness, expression, and processing have not been utilized. We evaluated treatment outcomes and predictors of outcomes of a novel emotionoriented intervention for chronic pain.

\section{Methods}

An initial individual session was conducted by one of the authors (HS) to assess medical conditions and review life stressors and symptom progression in order to identify linkages between stressors and symptoms. The treatment program consisted of 4 weekly small group 2-hour sessions. Components included readings, writing about emotions, mindfulness and emotional awareness exercises (on $\mathrm{CD}$ ), and other techniques to help people identify and process emotions related to stress and pain. Homework (e.g., writing, mindfulness exercises) was assigned daily. Patients were assessed at baseline by a research team and at post-treatment and 6-month follow-up. Included instruments were the Brief Pain Inventory (BPI) and the McGill Pain Questionnaire (MPQ).

\section{Results}

Fifty-nine adults with chronic musculoskeletal pain, primarily headaches, neck, back, and widespread pain (fibromyalgia), were included. Individuals with significant structural disease processes were excluded. Baseline demographics and characteristics were $76 \%$ women (mean age 51 years). 91\% Caucasian, mean duration of pain 8.8 years, and baseline pain level $5.03(0-10)$. Percent improvement was calculated for pain (\% change from baseline BPI score). At post-treatment $64 \%$ had $\geq$ $30 \%$ improvement and $43 \%$ had $\geq 50 \%$ improvement; at 6-months $67 \%$ had $\geq 30 \%$ improvement and $53 \%$ had $\geq$ $50 \%$ improvement. Mean BPI scores were 5.38, 3.04, and $3.03(\mathrm{p}<0.001, \mathrm{~d}=-1.27)$, respectively. The MPQ showed similar reductions.

\section{Conclusion}

This high rate of improvement may surpass that of cognitive-behavioral interventions for chronic pain. An approach focusing on confronting emotional contributions to pain appears beneficial. Studies with control groups are underway to determine if targeting unresolved stress and emotions offers an advance in the treatment of chronic non-structural pain.

\section{Author details}

${ }^{1}$ Providence Hospital, Wayne State University, Southfield, USA. ${ }^{2}$ Cedarville University, Cedarville, USA. ${ }^{3}$ Wayne State University, Detroit, USA.

Published: 12 June 2012

doi:10.1186/1472-6882-12-S1-P203

Cite this article as: Schubiner et al:: P02.147. Emotions matter: sustained reductions in chronic non-structural pain after a brief, manualized emotional processing program. BMC Complementary and Alternative Medicine 2012 12(Suppl 1):P203.

Providence Hospital, Wayne State University, Southfield, USA

Full list of author information is available at the end of the article 